\title{
Larval vision contributes to gregarious settlement in barnacles: adult red fluorescence as a possible visual signal
}

\author{
Kiyotaka Matsumura and Pei-Yuan Qian*
}

\begin{abstract}
Gregarious settlement, an essential behavior for many barnacle species that can only reproduce by mating with a nearby barnacle, has long been thought to rely on larval ability to recognize chemical signals from conspecifics during settlement. However, the cyprid, the settlement stage larva in barnacles, has one pair of compound eyes that appear only at the late nauplius VI and cyprid stages, but the function(s) of these eyes remains unknown. Here we show that cyprids of the intertidal barnacle Balanus (=Amphibalanus) amphitrite can locate adult barnacles even in the absence of chemical cues, and prefer to settle around them probably via larval sense of vision. We also show that the cyprids can discriminate color and preferred to settle on red surfaces. Moreover, we found that shells of adult $B$. amphitrite emit red auto-fluorescence and the adult extracts with the fluorescence as a visual signal attracted cyprid larvae to settle around it. We propose that the perception of specific visual signals can be involved in behavior of zooplankton including marine invertebrate larvae, and that barnacle auto-fluorescence may be a specific signal involved in gregarious larval settlement.
\end{abstract}

\section{KEY WORDS: Barnacle, Balanus amphitrite, Larval settlement,} Gregarious settlement, Cyprid larva, Compound eyes, Larval sense of vision, Settlement cue, Auto-fluorescence, Visual signal, Surface color, Zooplankton

\section{INTRODUCTION}

Barnacles are one of the most abundant fouling organisms, as well as dominant members of intertidal communities in the marine ecosystem. The life cycles of these crustaceans include six freeswimming nauplius larval stages followed by a non-feeding cyprid stage and sessile juvenile and adult stages. The cyprid larva is specialized for finding suitable substrate, attaching and metamorphosing into a juvenile. Larval attachment and metamorphosis, referred to as 'larval settlement', are crucial processes of the barnacle life cycle because juveniles and adults cannot move and therefore spend the rest of their life at the site chosen for settlement. Gregarious settlement is essential to many barnacle species, which are obligate cross-fertilizers that reproduce only by mating with nearby conspecifics. The cyprid larva has been thought to have specific environmental signal perception systems for gregarious settlement.

Since gregarious settlement in barnacles was first described by Knight-Jones and Stevenson (Knight-Jones and Stevenson, 1950), the chemical factors that elicit this behavior by cyprids have been studied primarily using Semibalanus balanoides (Crisp and

KAUST Global Collaborative Research Program, Division of Life Science,

The Hong Kong University of Science and Technology, Hong Kong.

*Author for correspondence (boqianpy@ust.hk)

Received 9 September 2013; Accepted 24 October 2013
Meadows, 1962; Crisp and Meadows, 1963; Larman et al., 1982). These studies revealed that gregarious settlement has a chemical basis and that proteins in the adult tissues induce cyprid settlement when the factor is adsorbed on the surface of substratum. In the 1990s, a novel glycoprotein named settlement-inducing protein complex (SIPC) was isolated from the adult barnacle, Balanus (=Amphibalanus) amphitrite, by bioassay-guided purification procedures (Matsumura et al., 1998a). SIPC induces settlement of conspecific cyprids if bound on the surface of substratum. After some characterization of this glycoprotein (Matsumura et al., 1998b; Matsumura et al., 1998c; Kato-Yoshinaga et al., 2000; Matsumura et al., 2000), the SIPC gene was cloned and sequenced, revealing a similarity of this settlement pheromone to the thioester-containing family of proteins (TEPs), which includes $\alpha 2$-macroglobulin (Dreanno et al., 2006a). SIPC was suggested to be involved in chemical communication between larvae as well as between larvae and adults (Matsumura et al., 1998c; Dreanno et al., 2006b). In addition, waterborne chemical cues have been proposed to induce larval settlement (Clare and Matsumura, 2000), and a $32 \mathrm{kDa}$ protein was recently identified as a waterborne settlement pheromone released by adult $B$. amphitrite (Endo et al., 2009). However, these chemical cues may attract cyprids only in very close proximity to adults (Elbourne and Clare, 2010). No factors other than chemical cues have been shown to be involved in species-specific gregarious settlement, although environmental factors, such as the presence of biofilms (Qian et al., 2003), tidal height (Grosberg, 1982), salinity (Dineen and Hines, 1994), water current (Crisp, 1955), the surface structure of the substratum (Crisp and Barnes, 1954; Wethey, 1984) and light conditions (Crisp and Ritz, 1973), have been shown to affect larval settlement behavior in barnacles.

Fales (Fales, 1928) reported the development of light perceptive organs in the larval and adult stages of the barnacles Balanus eburneus and Balanus (Semibalanus) balanoides. Barnacle larvae have a single simple eye (the larval median eye), called the "nauplius eye', which is present from hatching to settlement. The components of the nauplius eye differentiate into adult ocelli (Takenaka et al., 1993). Larvae also develop a pair of compound eyes that appear only in the late nauplius VI and cyprid stages and completely disappear during their metamorphosis to the juvenile. Although a morphological study of these compound eyes in cyprids has been carried out (Hallberg and Elofsson, 1983), their function and molecules involved in larval photo-reception have not been discovered. Cyprid compound eyes might be expected to play a role in larval settlement because these eyes appear only during the settlement stage. It has been suggested that the pair of widely separated compound eyes may be used in the selection of visual sensory input during settlement, which cannot be mediated by the small single nauplius eye (Hallberg and Elofsson, 1983; Barnes et al., 1951; Harrison and Sandeman, 1999). Furthermore, the cyprid has a well-developed brain and nervous system, which is poorly developed in the nauplius stages and almost completely absent in 
A

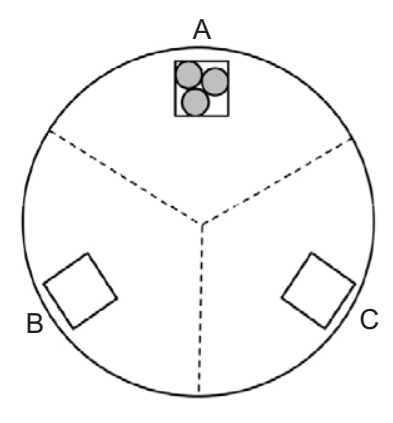

B

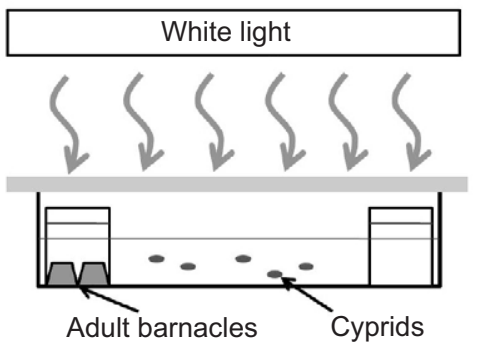

D

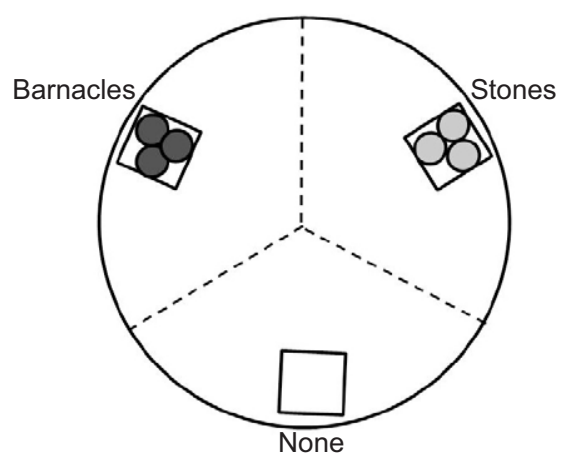

C

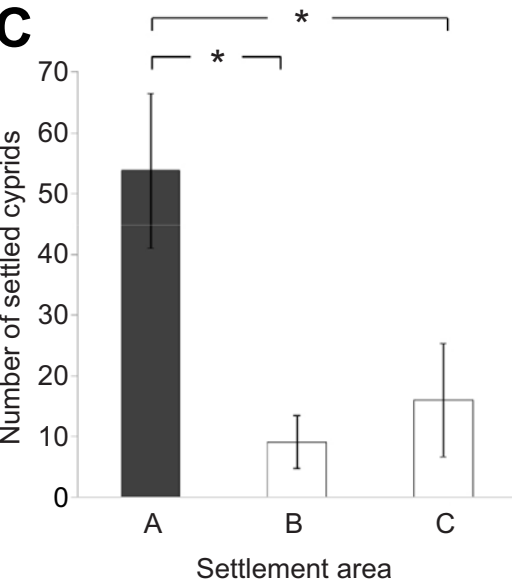

$\mathbf{E}$

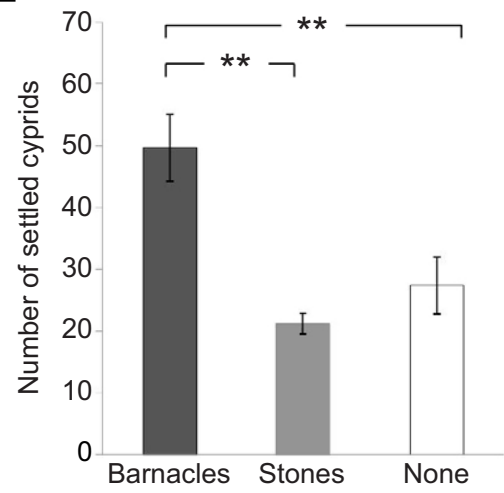

Fig. 1. Larval settlement assays for visual signal involvement using adult barnacles. $(A, B)$ Three UVtransparent polycarbonate boxes were placed in a PVC container, with one of the boxes housing five to 10 adult barnacles. Then, 200 cyprids were incubated in the container under a broad-spectrum white light. The container was covered with a UV-transparent polycarbonate sheet. (C) After $72 \mathrm{~h}$, cyprid settlement sites in the container were observed. The number of settlers in each area (A, B or C) was plotted. Data are means \pm s.e.m. of four replicate trials using four different batches of larvae $(N=4)$. (D) Three UV-transparent polycarbonate boxes were placed in a large glass Petri dish covered with a black sheet outside the bottom and side walls, with one of the boxes housing five to 10 adult barnacles and another box housing five to 10 stones. Then, 200 cyprids were placed in the container under white light. The Petri dish was covered with a UV-transparent sheet. (E) After $72 \mathrm{~h}$, cyprid settlement sites in the container were observed. The settlement in each area is plotted. Data are means \pm s.e.m. of five replicate trials using five different batches of larvae $(N=5)$. Asterisks indicate significant differences between numbers of settlers (Mann-Whitney U-test, $\left.{ }^{*} P<0.05,{ }^{*} P<0.01\right)$. the adult barnacle (Harrison and Sandeman, 1999; Walley, 1969), suggesting that cyprids need to sort and process inputs from various sense organs, including the eyes, and coordinate an appropriate behavioral response. To date, however, there have been no reports on the function of cyprid vision other than some studies on the response of barnacle larvae to light (phototaxis) (Crisp and Ritz, 1973; Visscher and Luce, 1928; Lang et al., 1979).

The Crustacea contain an amazing, and often bizarre, array of visual systems. This diversity includes many different examples of both simple and compound eyes (Cronin and Porter, 2008). The compound eyes of crustaceans are characterized by a variable number (a few to thousands) of small eyes, called ommatidia, which function as independent photoreception units within an optical system. The compound eye forms a 'neural picture' by the photoreceptors in the ommatidia, which are oriented to receive light from different directions, defined by the optics of the ommatidia, the curvature of the eye and the spacing arrangement and density of the ommatidia (Land, 1981; Stavenga, 2006). Hallberg and Elofsson (Hallberg and Elofsson, 1983) reported that the compound eye of barnacle cyprid larvae comprised approximately only 10 ommatidia, but the ommatidia are well differentiated morphologically, ensuring a visual function not inferior to that of many crustaceans with limited demand for visual performance. In seeking to determine the function of barnacle cyprid eyes, we hypothesized that cyprids use their compound eyes to identify appropriate settlement sites during the settlement process. In this study, we designed larval settlement assays to examine whether barnacle cyprids can discriminate adult barnacles for selecting settlement sites using their sense of vision.

\section{RESULTS}

Cyprids can discriminate conspecific adults by sense of vision during settlement

We designed a larval settlement assay for Balanus (Amphibalanus) amphitrite Darwin 1854 cyprids to determine whether the cyprid larvae of this species recognize conspecific adults without chemical signals. Five to 10 adult barnacles were placed in an ultraviolet (UV)-transparent box (Fig. 1) such that the adult barnacles were visible from anywhere within the container but the cyprid larvae had no contact with any chemical cues from the adults. In the first assay, in which visible and UV light were provided, the number of cyprids that settled over a $72 \mathrm{~h}$ period differed significantly among the three areas (A, B and C) of the container (Mann-Whitney $U$-test: A versus $\mathrm{B}, N=4, U=0, P=0.0143$; A versus $\mathrm{C}, N=4, U=2, P=0.0286$; $\mathrm{B}$ versus C, $N=4, U=6, P>0.1)$. The number of settlers in area A of the container, close to the box accommodating the adults, was four to five times higher than in the two other areas (B and C), which had empty boxes (no adult barnacles) (Fig. 1C). The second assay, which included adult barnacles in one area and stones similar in size to the adults in the other areas of the container (Fig. 1D), showed that the cyprids could discriminate between the adult barnacles and the 


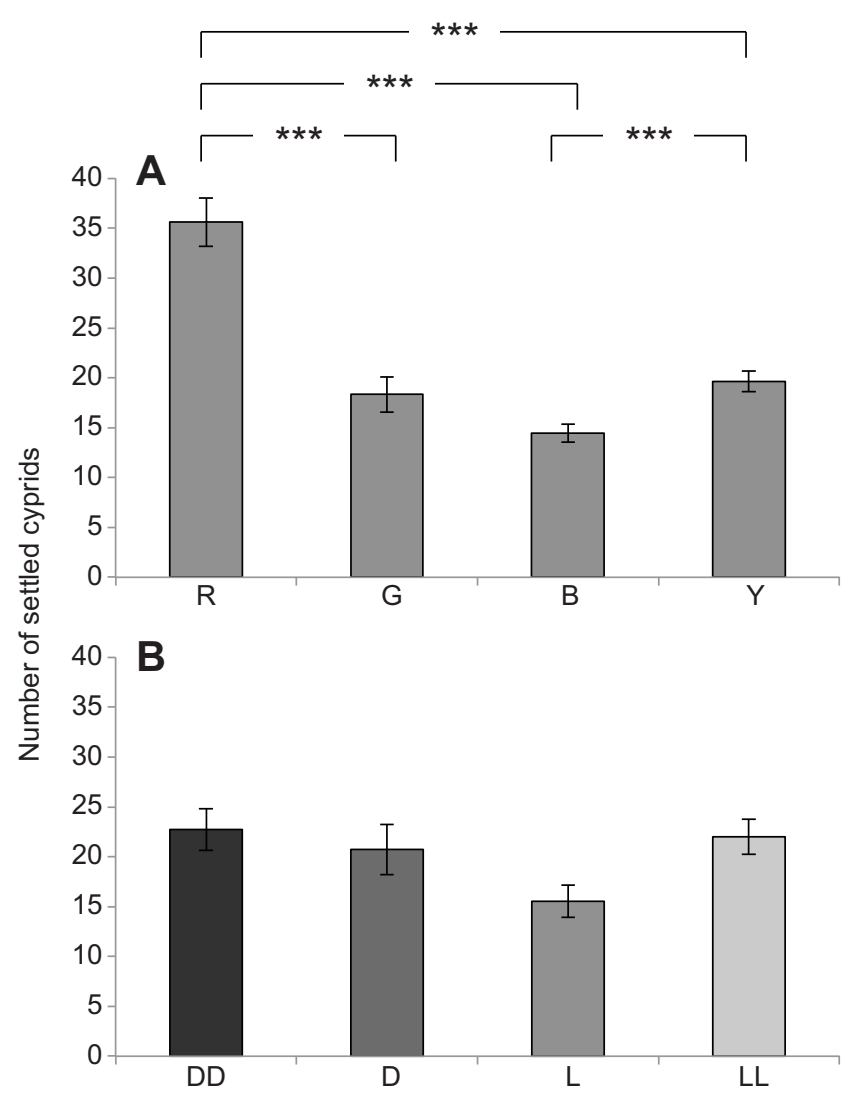

Fig. 2. Larval settlement assays for color discrimination. (A) Mean ( \pm s.e.m.) numbers of settled cyprids on red $(R)$, green $(G)$, blue $(B)$ and yellow $(Y)$ surfaces in each Petri dish. (B) Mean ( \pm s.e.m.) numbers of settled cyprids on gray surfaces with different levels of brightness: DD, darkest; D, second darkest; L, second lightest; LL, lightest. Three different batches of cyprids with five replicates in each batch were used $(N=15)$. Asterisks indicate significant differences between numbers of settlers (Mann-Whitney $U$-test, $\left.{ }^{* *} P<0.001\right)$. In the color discrimination assay $(\mathrm{A})$, the number of settlers on red surfaces was significantly higher than that on the other colors. In the gray assay (B), no significant differences between numbers of settlers on surfaces of different brightness were detected.

stones (Fig. 1E). Numbers of settlers were significantly different among the three treatment areas (Mann-Whitney $U$-test: barnacles versus stones, $N=5, U=0, P=0.00397$; barnacles versus none, $N=5$, $U=0.5, P=0.00397$; stones versus none, $N=5, U=6.5, P>0.01$ ), with settlement near the adult barnacles 1.8-2.3 times higher than in the two other areas. These results suggest that $B$. amphitrite cyprids use visual cues to locate adults during the settlement process.

\section{Cyprids can discriminate surface color of settlement site}

In the color discrimination assay, the maximal reflection wavelengths of the four color substrata were $638 \mathrm{~nm}$ for red, $559 \mathrm{~nm}$ for yellow, $511 \mathrm{~nm}$ for green and $499 \mathrm{~nm}$ for blue. Average numbers of settled cyprids on red, yellow, green and blue were 35.6, 19.7, 18.3 and 14.5, respectively (Fig. 2A). The numbers of settled cyprids on the red surface were significantly higher (1.8-2.5 times) than on the other colors (Mann-Whitney $U$-test, $N=15, P<0.001$ ). The settlement numbers on the yellow surface were higher than those on the blue surface, but settlement numbers were not significantly different between green and yellow, or between green and blue (Fig. 2A, supplementary material Fig. S1A).

However, these four surface colors showed different levels of brightness (darkness). Red was the darkest, and then in descending order of darkness was green, blue and yellow. Thus we used four different levels of gray with different brightness for a gray discrimination assay. The results showed that average numbers of settlement on the darkest (DD), second dark (D), second light (L) and the lightest (LL) gray surfaces were 22.7, 20.7, 15.5 and 22.0, respectively, and there was no significant difference in numbers of settled cyprids between the four gray surface colors (Mann-Whitney $U$-test, $N=15, P>0.001$; Fig. 2B, supplementary material Fig. S1B).

\section{Adult barnacle has red fluorescence}

When the adult barnacles were observed under a stereo fluorescence microscope with an SZX-FG filter (excitation: 510-550 nm, emission: $590 \mathrm{~nm}$ ), strong red fluorescence was detected on the surface of the barnacle shell plates (Fig. 3). This red fluorescence was not from surface biofilm on the shells but was tightly bound to or contained in the shells. The same fluorescence was also detected on opercula plates (tergum and scutum), although it was not distributed on the whole surface. Soft tissues inside the shells did not contain strong red fluorescence.

\section{Fluorescent substance(s) in adult barnacle extracts}

We tried to extract red fluorescent substance from adult $B$. amphitrite and succeeded in extraction in $50 \mathrm{mmol}^{-1}$ Tris- $\mathrm{HCl}$, $\mathrm{pH} 7.5$ containing $1 \mathrm{mmol}^{-1}$ dithiothreitol (DTT) (=TD buffer). The red fluorescence intensity of the extracts without DTT decreased when stored at room temperature, but DTT was found to stabilize the fluorescence in the extracts. The fluorescence intensity at different excitation and emission wavelengths of the extract solution is shown in Fig. 4A. The maximal fluorescence was detected by the fluorometer at an excitation/emission wavelength of 530/590 nm. When the adult crude extracts were treated at $100^{\circ} \mathrm{C}$ for $10 \mathrm{~min}$, the red fluorescence (530/590 $\mathrm{nm}$ excitation/emission) disappeared. The fluorescent intensity also drastically decreased to less than $3 \%$ of the crude extracts after ultra-filtration with a $30 \mathrm{kDa}$ membrane filter, suggesting that the fluorescent substance had a high molecular weight (Fig. 4B). To examine localization of the red fluorescence, barnacle shells and soft tissues were separated and extracted. The shell extracts had strong red fluorescence while the extracts from soft tissues had weak fluorescence, suggesting that most of the fluorescent substance is localized in the shells (Fig. 4B). In the fluorescence spectrum analysis, maximum excitation and emission wavelengths of the barnacle crude extracts were detected at $540-550 \mathrm{~nm}$ and $570-580 \mathrm{~nm}$, respectively (supplementary material Fig. S2).

\section{Cyprids may be attracted by barnacle red fluorescent substance(s)}

We designed a cyprid settlement assay using a polystyrene Petri dish and three polystyrene boxes made from cuvettes to examine whether cyprids can detect red fluorescence in the barnacle extracts as a visual signal (Fig. 5). When the crude extracts with red fluorescence were contained in one of three boxes, the number of cyprids that settled during $48 \mathrm{~h}$ differed significantly among the three areas of the Petri dish. The number of settlers in the area of the Petri dish closest to the box containing adult extracts was higher than in the two other areas that had boxes with filtered seawater (FSW). The number of settlers in the area with a box containing a high concentration of crude extracts $\left(2 \mathrm{mg} \mathrm{ml}^{-1}\right)$ was 2-2.5 times higher than in the two other areas (Mann-Whitney $U$-test, $N=9, P<0.01$; Fig. 5B), and the number of settlers in the area with a low concentration of crude extracts $\left(0.2 \mathrm{mg} \mathrm{ml}^{-1}\right)$ was 1.8 times higher ( $N=9, P<0.01$, Mann-Whitney $U$-test; Fig. 5C). However, under 

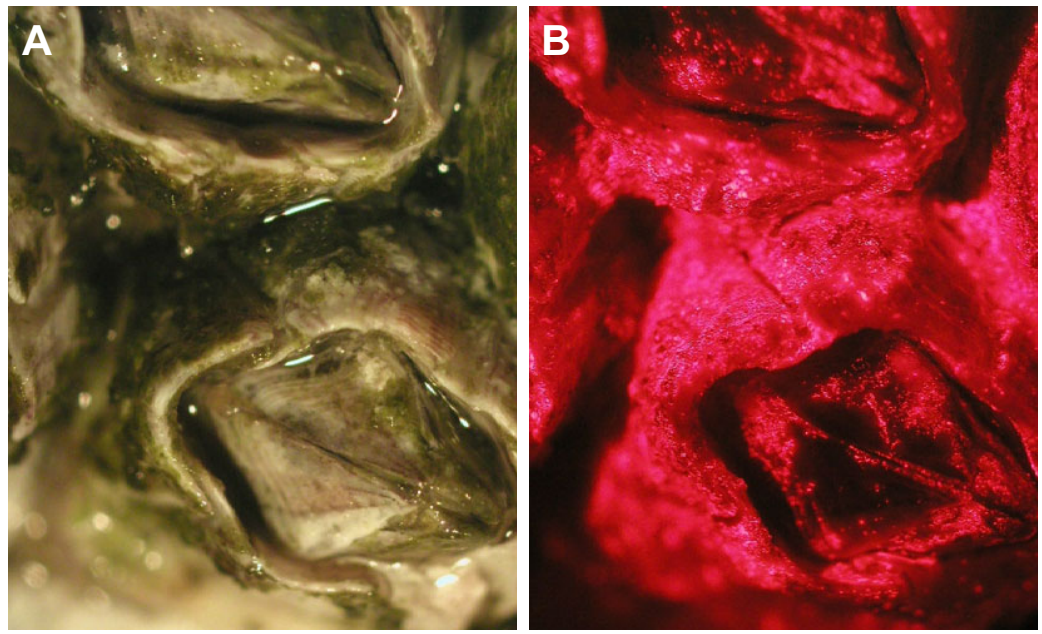

Fig. 3. Adult Balanus amphitrite has red auto-fluorescence.

(A) A photograph of adult $B$. amphitrite under a stereo microscope with normal light. (B) A photograph of the same barnacles under a fluorescence stereo microscope with an SZX-FG filter (excitation: $510-550 \mathrm{~nm}$, emission: $590 \mathrm{~nm}$ ). Strong red fluorescence was detected on the surface of the barnacle shell plates.

dark conditions (covered with aluminium foil), no significant difference was detected in the number of settlers between the area with crude extracts and the two other areas (Mann-Whitney $U$-test, $N=9, P>0.01$; Fig. 5F). Moreover, when the heated extracts with no red fluorescence were used, the number of settlers in the area with the heat extracts was not significantly higher than in the two other areas (Fig. 5D,E).

\section{DISCUSSION}

Selection of suitable settlement sites in larvae of sessile marine invertebrates is a crucial process for survival and reproduction. In many barnacle species, gregarious settlement is also essential to ensure that mating neighbors are sufficiently close once the individual becomes an adult. Since the 1950s, cyprid responses to chemical cues from conspecifics have been thought to be one of the most important mechanisms leading to conspecific gregarious settlement in barnacles, and two types of proteinaceous settlement cues have been purified from the adult $B$. amphitrite (Matsumura et al., 1998a; Dreanno et al., 2006a; Endo et al., 2009). However, the effective area of these chemical cues in the ocean may be limited (Elbourne and Clare, 2010), and other specific factors are possibly involved in their gregarious settlement behavior. This is the first study to confirm the role of a non-chemical cue in the process of gregarious settlement. Here we propose the involvement of a specific red fluorescent visual signal from adult barnacles and larval sense of vision in selection of larval settlement sites in barnacles.

Our bioassay results indicate that $B$. amphitrite cyprids can locate the adult barnacles and settle around them even without chemical signals (Fig. 1), indicating that cyprids do locate conspecific adults using their sense of vision. It is possible that cyprids have a highly developed sense of vision and can detect specific signals from the adults. Actually, we also found that cyprids of this species could discriminate color and preferred to settle on red surfaces (Fig. 2). Moreover, we showed that red fluorescence was detected on the shells of $B$. amphitrite, and that the fluorescent substance extracted from the adults attracted cyprids (Figs 3-5), while the extracts did not attract cyprids under dark conditions. Therefore, the red fluorescence on the shells of adult $B$. amphitrite might be a specific visual signal for conspecific cyprids.

Adult $B$. amphitrite colonize the intertidal zone of warm and temperate seas of the world, and the settlement sites of this species are generally exposed to sunlight, including UV radiation. During larval settlement, barnacle cyprids search for suitable settlement sites on the surface of the substratum under sunlight. Actually, light is considered to be an important physical cue to which barnacle larvae can respond before and during settlement (Crisp and Ritz, 1973). Field studies on diel fluctuations in barnacle settlement have revealed that cyprids of several intertidal and subtidal species, including B. amphitrite, settle in greater numbers during daytime than at night (Weiss, 1947; Daniel, 1957; Raimondi, 1990; Kado et al., 1997; Cruz et al., 2005). In contrast, Chiang et al. (Chiang et al., 2003; Chiang et al., 2007) found that intense UV-B radiation can induce ocular damage in barnacle larvae, thereby impairing the phototactic behavior of naupliar larvae. However, the nauplius eyes of nauplii larvae were most sensitive to UV-B, followed by the nauplius eyes of cyprids, while the compound eyes of cyprids sustained the least damage (Chiang et al., 2003), suggesting that cyprid compound eyes may function even in the presence of UV radiation in shallow-water areas for larval settlement.

The present study revealed that cyprid vision, probably using the compound eyes, plays an important role in searching for a settlement site. Cyprids were even able to distinguish conspecific adults from similar-sized objects such as stones (Fig. 1E). Moreover, they could discriminate color on the settlement surface and preferred to settle on red (Fig. 2), and also distinguished adult extracts with red fluorescence in the transparent box from seawater in the boxes using their sense of vision (Fig. 5). These results suggest that adult barnacles have specific visual signals, which may be their red fluorescence, and that cyprids may have a highly advanced photoreception system to recognize the red fluorescence via the compound eyes. The ommatidia of cyprid compound eyes are well differentiated morphologically (Hallberg and Elofsson, 1983), which is thought to ensure their well-developed visual function. The unique development of compound eyes in the late nauplius VI and cyprid larvae of barnacle indicates that stage-specific functions in the photoreception system may be associated not only with morphological differences in eyes but also with differences in photoreceptor proteins (opsins) of eyes.

A few studies have reported biological fluorescence as a visual signal for behavioral control in marine invertebrates. The optical properties of the aquatic environment spectrally filter both the incident and the reflected light. In addition, fluorescence has a greater potential to contribute to color underwater than in terrestrial situations, because the spectrum of the emitted light can contrast effectively with that of the predominantly blue illumination (Lythgoe, 1979). Fluorescent pigments contribute to the coloration of many corals and sea anemones (Dove et al., 2001; Mazel and Fuchs, 2003; Oswald et al., 2007). Unlike red and orange color resulting from subtraction 

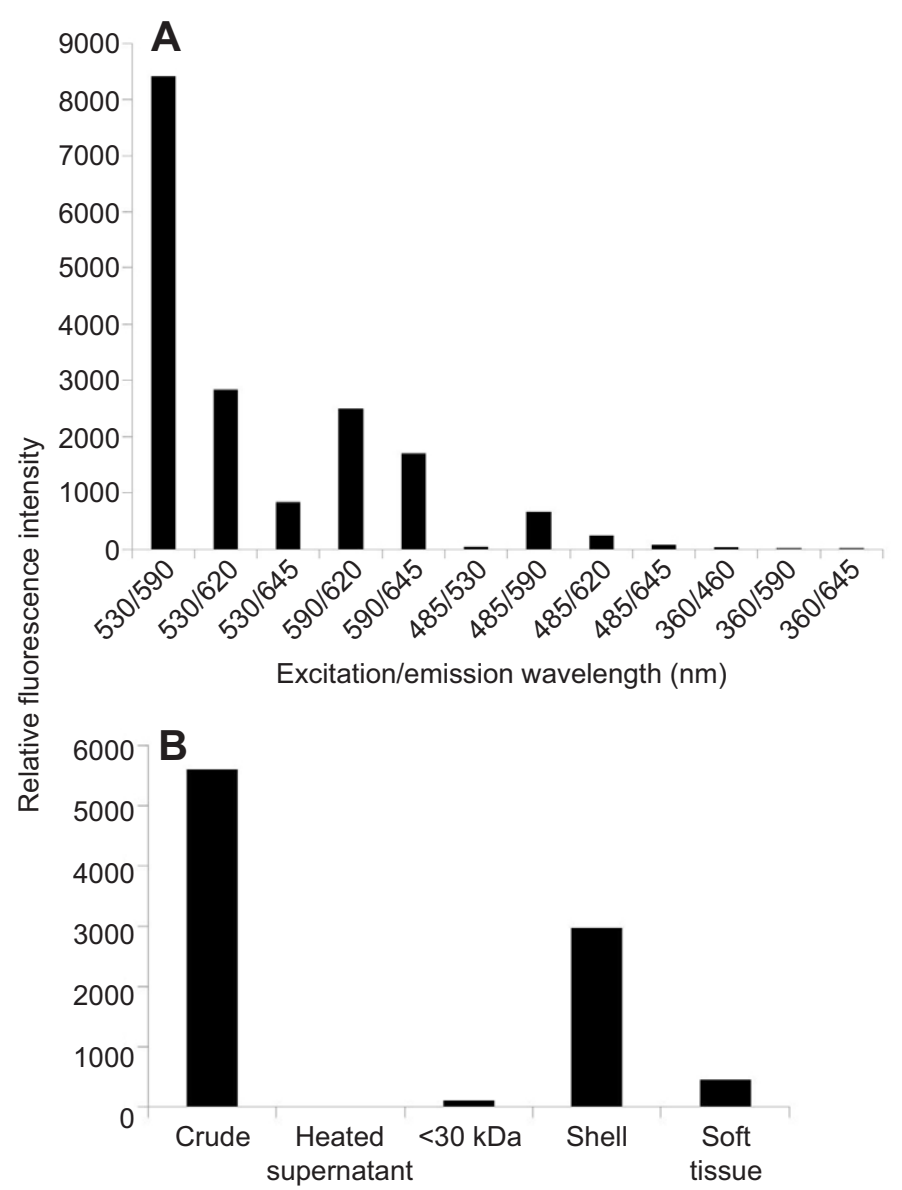

Fig. 4. Fluorescence intensity in barnacle extracts. Crude extracts $\left(3.5 \mathrm{mg} \mathrm{ml}^{-1}\right)$ were prepared from the adult barnacles, $B$. amphitrite, in $50 \mathrm{mmol} \mathrm{I}^{-1}$ Tris-HCl pH 7.5 containing $1 \mathrm{mmol} \mathrm{I}^{-1}$ dithiothreitol (=TD buffer). Fluorescence intensity of the crude extracts was measured with a fluorometer (CytoFluor II Microplate Reader, PerSeptive Biosystems). (A) Relative fluorescence intensity of the crude extracts at each excitation/emission wavelength (nm). (B) Relative fluorescence intensity of crude extracts, heat-treated supernatant, $<30 \mathrm{kDa}$ fraction, shell extracts and soft tissue extracts at 530/590 nm excitation/emission wavelength. Each sample was prepared from the same mass $(20 \mathrm{~g})$ of barnacles in the same volume $(20 \mathrm{ml})$ of TD buffer.

radiances (pigments absorbing blue and green wavelengths but reflecting red or orange), red and orange fluorescence can be brighter than the incident light of those wavelengths and, at greater depths, can create vivid color displays that contrast dramatically with the predominantly blue surroundings (Lythgoe, 1979). Recently, Mason et al. (Mason et al., 2011) reported that coral larvae settled at a higher frequency on red surfaces, and fluorescence and reflectance spectra of experimental substrata demonstrated that the preferred substrata had spectra dominated by wavelengths greater than $550 \mathrm{~nm}$ with little or no reflection or emission of shorter wavelengths. Although the molecular mechanisms of color and fluorescence discrimination in coral larvae have not been revealed, larvae of some species of coral may use spectral cues for fine-scale habitat selection during settlement (Mason et al., 2011). There are few reports published on fluorescence as visual signal in crustacean, but Mazel et al. (Mazel et al., 2004) showed that fluorescence enhanced the brightness and visibility of signaling in mantis shrimp. Mantis shrimp have a complex system of color vision, based on at least eight primary spectral receptor classes operating at wavelengths from 400 to $700 \mathrm{~nm}$, and colored markings play a crucial role in visual communication (Cronin et al., 2000). The fluorescent markings may be highly recognizable in a species-specific signaling system. However, several coral reef fish have speciesspecific red fluorescence and a novel signaling mechanism using the fluorescence pattern was proposed in intra-species communication (Michiels et al., 2008). In this study, we showed, for the first time, the red fluorescence in the intertidal barnacle $B$. amphitrite as a possible visual signal for gregarious larval settlement, and suggest that red fluorescence in the ocean, particularly in shallow water, may be an effective visual signal for some marine animals.

The primary function of a non-feeding cyprid larva, thought to be related to its well-developed nervous system, is to find a suitable place for survival, growth and reproduction (Harrison and Sandeman, 1999). The nervous system of the cyprid must be involved in behavioral responses to environmental signals via the peripheral organs, including the eyes, during settlement. Several reports of phototactic responses in zooplankton species, including marine invertebrate larvae such as barnacle cyprids, have been published (Crisp and Ritz, 1973; Kingsford et al., 2002; Jékely et al., 2008; Thiyagarajan et al., 2003).

This study indicates, for the first time, that barnacle larvae have the ability to locate adults using their sense of vision, and use vision to settle near conspecific adults by distinguishing their specific fluorescence. Visual signals such as specific fluorescence therefore likely affect the population dynamics of sessile organisms. Specific visual signals in addition to simple photo signals may contribute to the behavior of certain zooplanktons with advanced photoreception systems.

\section{MATERIALS AND METHODS}

\section{Animals}

Adult barnacles, Balanus (Amphibalanus) amphitrite, were collected from the concrete columns of the pier at Pak Sha Wan in Hong Kong $\left(22^{\circ} 21^{\prime} 45^{\prime \prime} \mathrm{N}, 114^{\circ} 15^{\prime} 35^{\prime \prime} \mathrm{E}\right)$ and were transferred to the laboratory. The nauplii larvae they released were reared to the cyprid stage in the laboratory (Thiyagarajan et al., 2003). Nauplii were cultured at $28^{\circ} \mathrm{C}$ with a diet of $10^{6}$ cells ml $^{-1}$ Chaetoceros gracilis, and generally reached the cyprid stage after 4 days. The cyprids were harvested and used for the settlement assays after being stored at $4^{\circ} \mathrm{C}$ in the dark overnight.

\section{Larval settlement assays using adult barnacles}

As shown in Fig. 1A,B, for the first bioassay, three UV-transparent polycarbonate boxes $(50 \times 50 \times 50 \mathrm{~mm})$ were placed in a circular gray PVC container $(250 \mathrm{~mm}$ in diameter) with one of the boxes housing five to 10 adult barnacles. The polycarbonate boxes were fixed on the bottom of the PVC container with double-sided carbon adhesive tape. The polycarbonate boxes and PVC containers were cleaned with neutral detergent and rinsed with tap water for more than $48 \mathrm{~h}$. New containers were used for every assay to avoid any influence of remaining chemical substances from settled cyprids and juveniles in the previous experiments, even after cleaning of the used containers. The UV-transparent boxes were watertight and did not allow seawater or chemicals through to the seawater out of the boxes in the PVC container. Two hundred cyprids in filtered seawater (FSW) were then added to the container, which was placed under white light at $25^{\circ} \mathrm{C}$. The container was covered with a UV-transparent sheet (Palram, Hong Kong). After $72 \mathrm{~h}$, the location of each settled cyprid in the container was recorded.

The second bioassay, to discriminate between barnacles and stones, was designed as follows (Fig. 1D). Three UV-transparent polycarbonate boxes $(30 \times 30 \times 30 \mathrm{~mm})$ were placed in a large glass Petri dish $(190 \mathrm{~mm}$ in diameter) covered with a black sheet outside the bottom and side walls, with one of the boxes housing five to 10 adult barnacles, another box housing five to 10 stones of similar size, shape and color to the barnacles, and the third box empty. Two hundred cyprids were then placed in the large Petri dish under white light. The Petri dish was covered with a UV- 
A
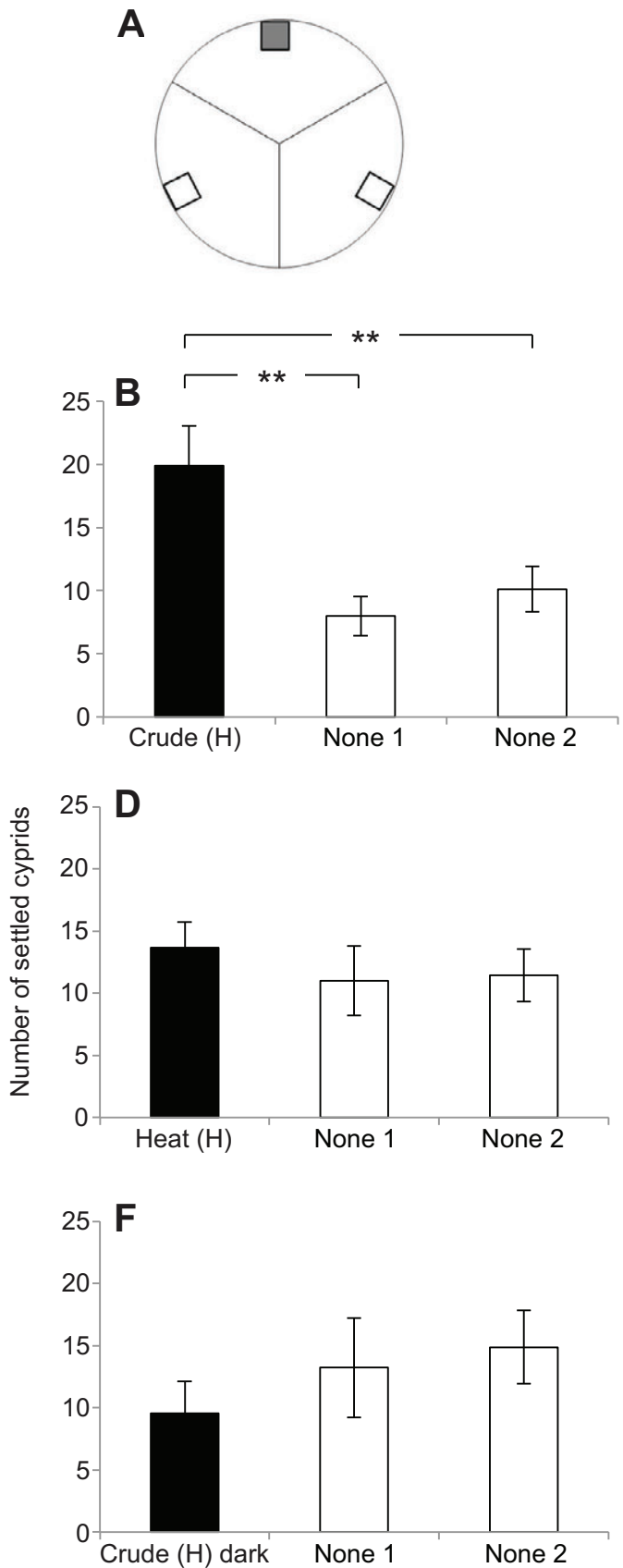
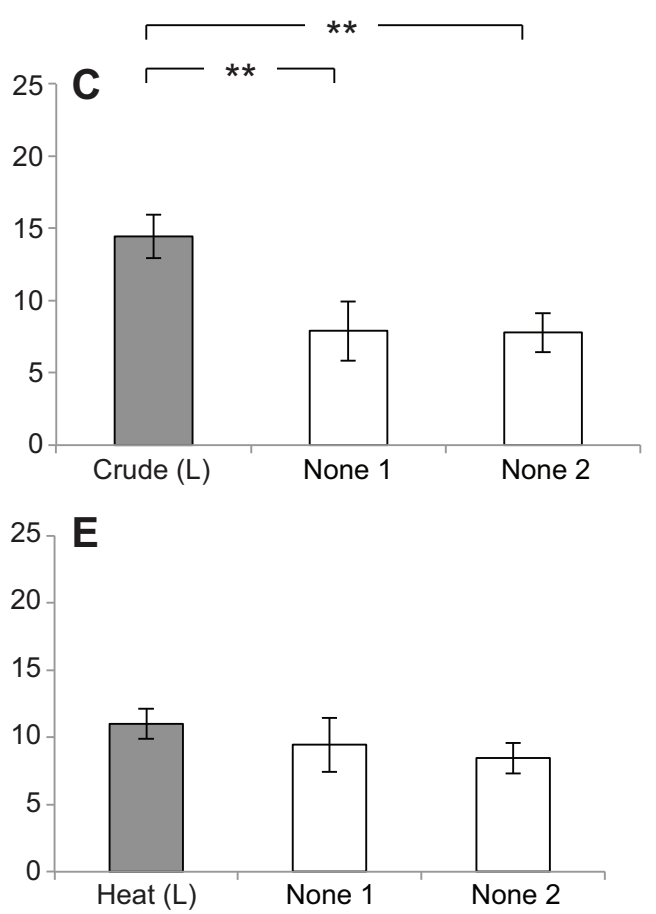

Fig. 5. Larval settlement assay using adult extracts with red fluorescence. (A) Three UVtransparent polystyrene boxes were placed in a polystyrene Petri dish, with one of the boxes containing barnacle extracts. Then, 50 cyprids were incubated in the Petri dish under white light. After $48 \mathrm{~h}$, cyprid settlement sites in the Petri dish were observed. (B-F) Mean ( \pm s.e.m.) numbers of settled cyprids in each area (adult extracts, none 1 and none 2). Barnacle extracts varied as follows: under light conditions, one box contained (B) a high concentration of crude extracts $\left(2 \mathrm{mg} \mathrm{ml}^{-1}\right),(\mathrm{C})$ a low concentration of crude extracts $\left(0.2 \mathrm{mg} \mathrm{ml}^{-1}\right),(\mathrm{D})$ a high concentration of heat-treated supernatant or $(E)$ a low concentration of heat-treated supernatant; $(F)$ under dark conditions, one box contained a high concentration of crude extracts $\left(2 \mathrm{mg} \mathrm{ml}^{-1}\right)$. Three different batches of cyprids with three replicates in each batch were used for the assays $(N=9)$. Asterisks indicate significant differences between numbers of settlers (Mann-Whitney U-test, $\left.{ }^{* *} P<0.01\right)$. transparent sheet (Palram). After $72 \mathrm{~h}$, cyprid settlement sites in the container were observed. The number of settled cyprids in each area (barnacles, stones or none) was plotted.

The illuminance in the assay container covered with the UV-transparent sheet under the white light was measured by a light meter (UVP, Upland, CA, USA). The illuminance in the container was approximately $6500 \mathrm{~lx}$ and no significant differences were detected between areas. Just in case, the position of the box with adult barnacles was changed in each assay to avoid any effect of slight differences in light conditions between areas.

\section{Larval settlement assays for color discrimination}

To examine whether cyprids can discriminate surface color of the substratum during settlement, a color selection assay was designed. The outside bottom and side wall of the polystyrene Petri dish $(90 \mathrm{~mm}$ diameter, Nunc, no. 172958, Penfield, NY, USA) were covered with four different colored papers (red, green, blue and yellow) or four gray papers of different brightness (Fig. 2, supplementary material Fig. S1). Fifty cyprids were placed in each Petri dish with $30 \mathrm{ml} \mathrm{FSW}$. They were incubated under white light at $25^{\circ} \mathrm{C}$. The illuminance in the Petri dish was approximately $6500 \mathrm{~lx}$ and no significant differences were detected. Just in case, the position of each color was changed in replicate dishes to avoid any effect of slight differences in light conditions between areas. After $48 \mathrm{~h}$, cyprid settlement sites in the Petri dish were observed. The number of settled cyprids in each area was plotted.

\section{Observation of auto-fluorescence in adult barnacles}

Adult barnacles were observed under a stereo fluorescence microscope (Olympus SZX12, Tokyo, Japan) with an SZX-FG filter (excitation: 510-550 nm, emission: $590 \mathrm{~nm}$ ).

\section{Preparation of barnacle extracts containing red fluorescence}

The surface of the collected adult barnacles was cleaned with a soft brush in FSW, and then the barnacles were kept in $-80^{\circ} \mathrm{C}$ until use. To prepare barnacle extracts with fluorescence, the whole bodies $(25 \mathrm{~g})$ were crushed in $25 \mathrm{ml}$ (equal mass of adult barnacles) of $50 \mathrm{mmol}^{-1}$ Tris- $\mathrm{HCl}, \mathrm{pH} 7.5$ containing $1 \mathrm{mmol}^{-1}$ dithiothreitol (DTT) $(=\mathrm{TD}$ buffer) using a mortar and pestle. The homogenate was centrifuged at $15,000 \mathrm{~g}$ for $30 \mathrm{~min}$. The 
supernatant was filtered with a $0.22 \mu \mathrm{m}$ cartridge membrane filter, and the resultant solution (=intact barnacle extracts) was stored at $-80^{\circ} \mathrm{C}$ until use. For preparation of the heat-treated solution, the intact barnacle extracts were heated at $100^{\circ} \mathrm{C}$ for $10 \mathrm{~min}$, then centrifuged at $15,000 \mathrm{~g}$ for $30 \mathrm{~min}$, and the supernatant ( $=$ heated barnacle extracts) was stored at $-80^{\circ} \mathrm{C}$ until use. For preparation of shell extracts and soft tissue extracts, soft tissues were separated from the adult barnacles $(20 \mathrm{~g})$, and the shells and soft tissues were each crushed in $20 \mathrm{ml}$ of TD buffer.

\section{Measurement of fluorescence intensity in barnacle extracts}

The fluorescence intensity of sample solution was measured with a fluorometer (CytoFluor II Microplate Reader, PerSeptive Biosystems, Framingham, MA, USA), and the fluorescent spectrum was measured with an SLM 8000 Spectrofluorimeter (SLM Instruments, Inc., Urbana, IL, USA).

\section{Larval settlement assay using adult extracts with red fluorescence}

The adult barnacle extracts with red fluorescence were used for a larval settlement assay to examine whether cyprids can detect red fluorescence in the extracts as a visual signal. As shown in Fig. 5A, three UV-transparent polystyrene boxes $(10 \times 10 \times 15 \mathrm{~mm})$ made from fluorimeter cuvettes $(\mathrm{C} 0918$ 100EA, Sigma-Aldrich, St Louis, MO, USA) were placed in a polystyrene Petri dish (90 mm diameter, Nunc, no. 172958) covered with a black sheet outside the bottom and side walls, with one of the boxes containing $600 \mu \mathrm{l}$ test solution and the other two containing $600 \mu \mathrm{FSW}$ each. The boxes were fixed on the bottom of the Petri dish with double-sided carbon adhesive tape. Fifty cyprids were placed in each Petri dish with $30 \mathrm{ml}$ FSW. The Petri dishes were set on a rotating table (1 r.p.m.) and were incubated under a white light at $25^{\circ} \mathrm{C}$. The illuminance in the Petri dish was approximately $6500 \mathrm{~lx}$ and the rotation mitigated the bias from external factors such as light direction. After $48 \mathrm{~h}$, the location of each settled cyprid in the Petri dish was recorded. The numbers of settled cyprids in each area were plotted. For the assay under dark conditions, the Petri dish was covered with aluminium foil.

\section{Acknowledgements}

The authors thank Dr Louis Gosselin of Thompson Rivers University for a critical reading of the manuscript.

\section{Competing interests}

The authors declare no competing financial interests.

\section{Author contributions}

K.M. designed and performed the experiments. K.M. and P-Y.Q. wrote the paper.

\section{Funding}

This study was supported by grants from the Research Grants Council of the Hong Kong Special Administrative Region (GRF662413 and AoE/P-04/04-II) and an award from the King Abdullah University of Science and Technology (SA-C0040/ UK-C0016) to P.-Y.Q.

\section{Supplementary material}

Supplementary material available online at

http://jeb.biologists.org/lookup/suppl/doi:10.1242/jeb.096990/-/DC1

\section{References}

Barnes, H., Crisp, D. J. and Powell, H. T. (1951). Observation on the orientation of some species of barnacles. J. Anim. Ecol. 20, 227-241.

Chiang, W. L., Au, D. W. -T., Yu, P. K.-N. and Wu, R. S.-S. (2003). UV-B damages eyes of barnacle larvae and impairs their photoresponses and settlement success. Environ. Sci. Technol. 37, 1089-1092.

Chiang, W. L., Wu, R. S.-S., Yu, P. K.-N. and Au, D. W.-T. (2007). Are barnacle larvae able to escape from the threat of UV? Mar. Biol. 151, 703-711.

Clare, A. S. and Matsumura, K. (2000). Nature and perception of barnacle settlement pheromones. Biofouling 15, 57-71.

Crisp, D. J. (1955). The behaviour of barnacle cyprids in relation to water movement over a surface. J. Exp. Biol. 32, 569-590.

Crisp, D. J. and Barnes, H. (1954). The orientation and distribution of barnacles at settlement with particular references to surface contour. J. Anim. Ecol. 23, 142-162.

Crisp, D. J. and Meadows, P. S. (1962). The chemical basis of gregariousness in cirripedes. Proc. R. Soc. B 156, 500-520.

Crisp, D. J. and Meadows, P. S. (1963). Adsorbed layers: the stimulus to settlement in barnacles. Proc. R. Soc. B 158, 364-387.
Crisp, D. J. and Ritz, D. A. (1973). Response of cirripede larvae to light. 1. Experiments with white light. Mar. Biol. 23, 327-335

Cronin, T. W. and Porter, M. (2008). Exceptional variation on a common theme: the evolution of crustacean compound eyes. Evol. Educ. Outreach 1, 463-475.

Cronin, T. W., Marshall, N. J. and Caldwell, R. L. (2000). Spectral tuning and the visual ecology of mantis shrimps. Philos. Trans. R. Soc. Lond. B 355, 1263-1267.

Cruz, T., Castro, J. J., Delany, J., McGrath, D., Myers, A. A., O'Riordan, R. M., Power, A.-M., Rabaça, J. and Hawkins, S. J. (2005). Tidal rates of settlement of the intertidal barnacles Chthamalus stllatus and Chthamalus montagui in Western Europe: the influence of the night/day cycle. J. Exp. Mar. Biol. Ecol. 318, 51-60.

Daniel, A. (1957). Illumination and its effect on the settlement of barnacle cyprids. Proc. Zool. Soc. Lond. 129, 305-313.

Dineen, J. F. and Hines, A. H. (1994). Effects of salinity and adult extract on settlement of the oligohaline barnacle Balanus subalbidus. Mar. Biol. 119, 423-430.

Dove, S. G., Hoegh-Guldberg, O. and Ranganathan, S. (2001). Major colour patterns of reef-building corals are due to a family of GFP-like proteins. Coral Reefs 19, 197-204

Dreanno, C., Matsumura, K., Dohmae, N., Takio, K., Hirota, H., Kirby, R. R. and Clare, A. S. (2006a). An a2-macroglobulin-like protein is the cue to gregarious settlement of the barnacle Balanus amphitrite. Proc. Natl. Acad. Sci. USA 103 14396-14401.

Dreanno, C., Kirby, R. R. and Clare, A. S. (2006b). Smelly feet are not always a bad thing: the relationship between cyprid footprint protein and the barnacle settlement pheromone. Biol. Lett. 2, 423-425.

Elbourne, P. D. and Clare, A. S. (2010). Ecological relevance of a conspecific, waterborne settlement cue in Balanus amphitrite (Cirripedia). J. Exp. Mar. Biol. Ecol. 392, 99-106.

Endo, N., Nogata, Y., Yoshimura, E. and Matsumura, K. (2009). Purification and partial amino acid sequence analysis of the larval settlement-inducing pheromone from adult extracts of the barnacle, Balanus amphitrite (=Amphibalanus amphitrite). Biofouling 25, 429-434

Fales, D. E. (1928). The light-receptive organs of certain barnacles. Biol. Bull. 54, 534547.

Grosberg, R. K. (1982). Intertidal zonation of barnacles: the influence of planktonic zonation of larvae on vertical distribution of adults. Ecology 63, 894-899.

Hallberg, E. and Elofsson, R. (1983). The compound eyes of barnacles. J. Crustac. Biol. 3, 17-24.

Harrison, P. J. H. and Sandeman, D. C. (1999). Morphology of the nervous system of the barnacle cyprid larva (Balanus amphitrite Darwin) revealed by light and electron microscopy. Biol. Bull. 197, 144-158.

Jékely, G., Colombelli, J., Hausen, H., Guy, K., Stelzer, E., Nédélec, F. and Arendt, D. (2008). Mechanism of phototaxis in marine zooplankton. Nature 456, 395-399. Kado, R., Okuyama, S. and Kurita, T. (1997). Diel fluctuations in settlement of subtidal barnacles in relation to environmental factors. Sessile Organisms 14, 1-8.

Kato-Yoshinaga, Y., Nagano, M., Mori, S., Clare, A. S., Fusetani, N. and Matsumura, K. (2000). Species specificity of barnacle settlement-inducing proteins. Comp. Biochem. Physiol. 125A, 511-516.

Kingsford, M. J., Leis, J. M., Shanks, A., Lindeman, K. C., Morgan, S. G. and Pineda, J. (2002). Sensory environments, larval abilities and local self-recruitment. Bull. Mar. Sci. 70, 309-340.

Knight-Jones, E. W. and Stevenson, J. P. (1950). Gregariousness during settlement in the barnacle Elminius modestus Darwin. J. Mar. Biol. Assoc. U. K. 29, 281-297.

Land, M. F. (1981). Optics and vision in invertebrates. In Handbook of Sensory Physiology, Vol. VII/6B (ed. H. Autrum), pp 472-592. Berlin: Springer.

Lang, W. H., Forward, R. B., Jr and Miller, D. C. (1979). Behavioral responses of Balanus improvisus nauplii to light intensity and spectrum. Biol. Bull. 157, 166-181.

Larman, V. N., Gabbott, P. A. and East, J. (1982). Physico-chemical properties of the settlement factor proteins from the barnacle, Balanus balanoides. Comp. Biochem. Physiol. 72B, 329-338.

Lythgoe, J. N. (1979). The Ecology of Vision. Oxford: Clarendon Press.

Mason, B., Beard, M. and Miller, M. W. (2011). Coral larvae settle at a higher frequency on red surfaces. Coral Reefs 30, 667-676.

Matsumura, K., Nagano, M. and Fusetani, N. (1998a). Purification of a larval settlement-inducing protein complex (SIPC) of the barnacle, Balanus amphitrite. J. Exp. Zool. 281, 12-20.

Matsumura, K., Mori, S., Nagano, M. and Fusetani, N. (1998b). Lentil lectin inhibits adult extract-induced settlement of the barnacle, Balanus amphitrite. J. Exp. Zool. 280, 213-219.

Matsumura, K., Nagano, M., Kato-Yoshinaga, Y., Yamazaki, M., Clare, A. S. and Fusetani, N. (1998c). Immunological studies on the settlement-inducing protein complex (SIPC) of the barnacle Balanus amphitrite and its possible involvement in larva-larva interactions. Proc. Biol. Sci. 265, 1825-1830.

Matsumura, K., Hills, J. M., Thomason, P. O., Thomason, J. C. and Clare, A. C. (2000). Discrimination at settlement in barnacles: laboratory and field experiments on settlement behaviour in response to settlement-inducing protein complexes. Biofouling 16, 181-190.

Mazel, C. H. and Fuchs, E. (2003). Contribution of fluorescence to the spectral signature and perceived color of corals. Limnol. Oceanogr. 48, 390-401.

Mazel, C. H., Cronin, T. W., Caldwell, R. L. and Marshall, N. J. (2004). Fluorescent enhancement of signaling in a mantis shrimp. Science 303, 51.

Michiels, N. K., Anthes, N., Hart, N. S., Herler, J., Meixner, A. J., Schleifenbaum, F., Schulte, G., Siebeck, U. E., Sprenger, D. and Wucherer, M. F. (2008). Red fluorescence in reef fish: a novel signalling mechanism? BMC Ecol. 8, 16.

Oswald, F., Schmitt, F., Leutenegger, A., Ivanchenko, S., D'Angelo, C., Salih, A., Maslakova, S., Bulina, M., Schirmbeck, R., Nienhaus, G. U. et al. (2007). 
Contributions of host and symbiont pigments to the coloration of reef corals. FEBS J. 274, 1102-1122.

Qian, P. Y., Thiyagarajan, V., Lau, S. C. K. and Cheung, S. C. K. (2003). Relationship between bacterial community profile in biofilm and the attachment of acorn barnacle Balanus amphitrite Darwin. Aquat. Microb. Ecol. 33, 225-237.

Raimondi, P. T. (1990). Patterns, mechanisms, consequences of variability in settlement and recruitment of an intertidal barnacle. Ecol. Monogr. 60, 283-309.

Stavenga, D. G. (2006). Invertebrate photoreceptor optics. In Invertebrate Vision (ed. E. Warrant and D. E. Nilsson), pp. 1-42. Cambridge: Cambridge University Press.

Takenaka, M., Suzuki, A., Yamamoto, T., Yamamoto, M. and Yoshida, M. (1993). Remodeling of the nauplius eye into the adult ocelli during metamorphosis of the barnacle Balanus amphitrite hawaiiensis. Dev. Growth Differ. 35, 245-255.
Thiyagarajan, V., Harder, T., Qiu, J. W. and Qian, P. Y. (2003). Energy content at metamorphosis and growth rate of the juvenile barnacle, Balanus amphitrite. Mar. Biol. 143, 543-554.

Visscher, J. P. and Luce, R. H. (1928). Reaction of the cyprid larvae of barnacles to light with special reference to spectral colors. Biol. Bull. 54, 336-350.

Walley, L. J. (1969). Studies on the larval structure and metamorphosis of Balanus balanoides (L.). Philos. Trans. R. Soc. Lond. B 256, 237-280.

Weiss, C. M. (1947). The effect of illumination and stage of tide on the attachment of barnacle cyrids. Biol. Bull. 93, 240-249.

Wethey, D. S. (1984). Spatial patterns in barnacle settlement: day to day changes during the settlement season. J. Mar. Biol. Assoc. U.K. 64, 687-698. 